\title{
Evidence for compliance with long-term medication: a systematic review of randomised controlled trials.
}

\begin{abstract}
Background

Pharmacists play a pivotal role in optimising medication use which often includes actions to maximise compliance with long-term medication. The best evidence to support medication use is derived from randomised controlled trials (RCTs). It is often assumed that $100 \%$ compliance is required to obtain the outcomes identified in the trial. This assumption needs to be examined.
\end{abstract}

Objective

To systematically review the reporting of compliance in RCTs of long-term medications.

Method

RCTs published in the New England Journal of Medicine, Journal of the American Medical Association, Lancet and BMJ in 2012, were reviewed to identify trials of medications for long-term use in adults. These trials were examined to evaluate the reporting of compliance.

Main outcome measures

The proportion of trials reporting compliance data, the methods used, and the proportion of trials using more than one method to determine compliance.

Results

Of the 289 RCTs published in 2012, 25 assessed long-term medications in adults. Compliance was reported in $12(48 \%)$ studies and only $2(8 \%)$ studies used more than one method to measure compliance. Pill count was the most commonly reported method for measuring compliance, with patient reports and blood levels also being used.

Conclusion

The reporting of compliance in RCTs is poor and the methodology inconsistent. The methods used overestimate compliance. If compliance in a clinical trial is low, the evidence for the effectiveness and most importantly safety of the medication(s) is questionable. Two or more methods, one of which is standardised, should be used to measure compliance in clinical trials. The requirement to report compliance should be included in publication guidelines.

Impact of findings on practice

- Compliance is underreported and underestimated in randomised controlled trials, therefore estimates of the difference between efficacy and effectiveness need to be revised. 
- Non-compliance in clinical trials can lead to overestimation of the effective dose and underestimation of the side effects, therefore pharmacists should consider the evidence before acting to maximise compliance.

- Standardised measures of compliance need to be developed and implemented so that adherence can be compared in different populations and situations.

Keywords (MeSH) - clinical trials, systematic reviews, medication adherence, chronic disease, pharmacoepidemiology

Introduction

The prevalence of chronic disease is increasing[1,2]. Consequently, the use of medication to treat chronic conditions is also increasing[3,4]. Ensuring optimal outcomes from medication is therefore a global priority in which pharmacists have a pivotal role. Patients need to take their medication in order for it to have an effect; therefore medication taking behaviour is important. The terminology however is less so. Epidemiologically it does not matter whether a patient is obedient (compliant), autonomous (adherent)[5]or collaborative (concordant), what matters is whether they take a dose. The term compliance has been chosen to represent the proportion of prescribed doses taken; other terminology is that used in the studies referenced.

Medication compliance in chronic conditions is less than that in acute conditions, with reports from clinical trials ranging between $43 \%$ and $78 \%[6]$. Compliance may decrease over time, for example, about half of the patients prescribed an anti-hypertensive had stopped taking it within one year[7]. Because compliance is lower in chronic conditions, pharmacists tend to focus on improving the compliance of patients taking long-term medication. In Australia in recent years, pharmacists have been remunerated for clinical interventions to improve compliance, for example intervening with a patient who "chooses to take a medicine PRN instead of on a regular basis (when the latter was intended)"[8].

From a public health planning point of view it is important to be able to assess the safety and efficacy of medications[9], in the populations that will be taking these medications. Safety and efficacy are closely linked with and usually depend upon compliance. The highest level of evidence for safety and efficacy comes from randomised controlled trials, yet the reporting of compliance in clinical trials is poor, identifying a serious defect in the quality of the evidence. Souter and Kennedy reported that only 19\% (61/324) of clinical trials published in the Lancet and BMJ between 1969 and 1972 reported compliance, with only $2 \%$ (6/324) using more than one method to assess compliance[10]. More than two decades later, in 1997-1999, Jayaraman et. al. reported that this had increased to $47 \%$ (78/165) with $16 \%$ of trials using more than one method of assessment[11]. In 2003, the WHO recommended, "A multi-method approach that combines feasible self-reporting and reasonable objective measures ...... in measurement of adherence behaviour" [9]. Because there are serious defects in the reporting of compliance in clinical trials, and with the increasing emphasis placed on medication compliance in chronic conditions, the aim of this study was to assess the 
reporting of compliance in randomised controlled trials (published in 2012) of medications for longterm use in non-institutionalised adults.

Method

The four highest ranked medical journals based on citations in Web of Science (Thomson Reuters), i.e. The New England Journal of Medicine (NEJM), The Journal of the American Medical Association (JAMA), The Lancet and the BMJ, were chosen for this systematic review. It was expected that the highest ranked journals would have the highest quality standards and therefore that the articles published in them would be the most likely to contain information on patient compliance. The Lancet and BMJ have been used in previous studies[10, 11].

Randomised controlled trials (RCTs) published in these journals in 2012 were identified using Ovid Medline (search term: journal name, limits: publication types - randomized controlled trial, and publication year - 2012). Titles and abstracts were manually searched to identify parallel design trials comparing medicines. The full text of these articles was then manually searched to identify studies that compared single named medicines or fixed dose combinations in a single dose unit (e.g. tablet or capsule), taken by mouth at least once or more a day, for a minimum of one month.

Exclusion criteria were chosen to maximise the clarity of our findings by limiting the background variation (noise) and confounding factors. Previous research has identified that the medication, dose form [12], route[13], complexity of the regimen[3, 6, 13, 14] and duration of treatment[7] can influence compliance and are therefore likely to add to background variation. Combinations of medicines where each drug needed to be taken as a separate tablet were therefore excluded. As were trials were the medicine was not administered by the most common route, i.e. orally; or if the dose frequency, number of tablets, or duration (within the trial) varied. Comparisons with 'best available therapy' if the medication was not named were also excluded as it was not possible to determine whether the other exclusion criteria applied or not.

Trials including children or those in institutions were excluded, as it was likely that these patients did not have either: personal responsibility for, or control over, their compliance.

Study descriptions and compliance data including the method of measuring compliance and the reported rate/s of compliance from the remaining articles were tabulated. 
Results

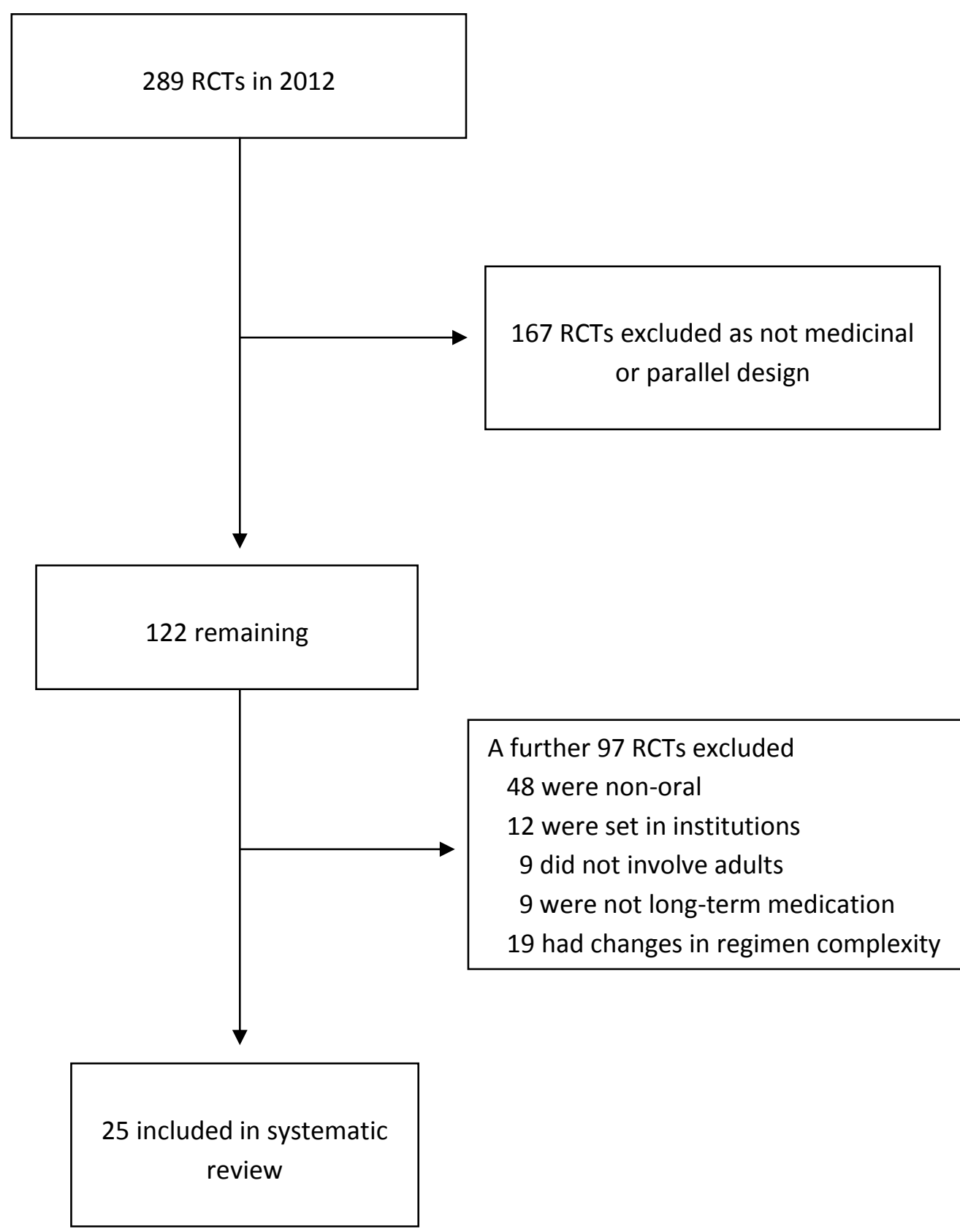

Figure 1 Selection process for systematic review

Of the 289 RCTs published in the NEJM, JAMA, Lancet and BMJ in 2012, only 122 were parallel comparisons of medicines (or medicine and placebo); 97 of these were eliminated based on the exclusion criteria, leaving 25 for inclusion in the systematic review (Fig 1). Of these articles 15 were from NEJM, 5 from JAMA, 5 from The Lancet and 0 were from the BMJ. Compliance was reported in 
$12(48 \%)$ studies (Table 1). (The study that used the proportion of patients in the treatment group discontinuing and proportion of patients in the placebo group commencing treatment as a measure of non-adherence was not counted as this 'adherence' was to the randomisation protocol rather than the study medication.) The method for detecting or assessing compliance was missing in 16 (64\%) studies. Of the studies that reported the detection method, three studies (12\%) used pill counts, two (8\%) used patient report, and one (4\%) used blood/cell concentration. Only 2 (8\%) studies, both focussing on HIV, used all three methods. The poor reporting of the detection methods, the variety of methods used, and the associated lack of a common denominator, prevented the calculation of an overall mean or range for compliance, for example, pill counts comparing the number of doses actually taken with the number that should have been taken cannot be compared with pill counts reporting the percentage of people taking between $80 \%$ and $120 \%$ of doses.

(Place table 1 here)

\section{Discussion}

The reporting of compliance in clinical trials for long-term medications is poor, with less than half of the trials including compliance data, and many of these failing to identify the measurement method used. In contrast to the NEJM and The Lancet all but one of the articles published in JAMA included the method of detection and compliance data. No trial published in the BMJ met our inclusion criteria.

The inclusion of one standardised method of measuring compliance in all trials would greatly improve comparisons across treatments and clinical trials. Little has changed since 2005 when Jayaraman et.al. noted that the reporting of compliance occurred in only $47 \%$ of clinical trials[11]. Despite WHO recommendations that two or more methods should be used to asses compliance[9], only 2 studies did this and both were assessing treatments for HIV where a high level of compliance is required to suppress the virus.[15] The recent publication of guidance for protocols of clinical trials[16], which recommends that procedures for monitoring adherence be included in trial protocols, may improve this situation in the future, however the reporting requirements for clinical trials, i.e. CONSORT guidelines[17], should be updated to reflect the importance of the publication of adherence data.

The variety of compliance measures used reflects methodological difficulties and raises some quality issues. The ideal method(s) of measuring compliance would be accurate, easy to perform, inexpensive and provide information on the number of doses taken, the correct timing of those doses and reasons for omitting or increasing doses. The most popular methods, i.e. pill count, patient report, drug (or marker) levels, and electronic monitoring, provide different, though complimentary, information on compliance. Each has its own pros and cons, but most overestimate compliance. Pill count is easy to perform and inexpensive[18], however it provides no information on the timing of doses and can be affected by lost pills or patients retaining or discarding pills instead of returning them $[6,18]$. Up to $30 \%$ of clinical trial participants may discard study medications[19]. 
Patient report is inexpensive[18] and can provide additional data as to why patients take too little or too much of their medication, unfortunately while it is a specific measure, in that reports of poor compliance are accurate, it is not sensitive, as poor compliers may not admit to missing doses or taking them at the wrong time $[5,13,19]$. There are numerous instruments to capture patient selfreports but all fail to accurately assess or explore one or more important facets of compliance or non-compliance[20]. The ideal instrument would be responsive, i.e. able to detect clinically important changes in compliance, reliable, validated against non-questionnaire methods, be suitable for use by patients and carers, and provide information on the cause of non-compliance, including being able to distinguish between intentional and unintentional compliance[20].

Levels of a medication (or a marker) that can be measured in body fluids accurately reflect compliance if the medication is completely absorbed, has a long half-life and $100 \%$ is excreted unchanged[10]. Assessing the compliance of medicines with shorter half-lives is confounded by white coat adherence, i.e. when patients increase compliance before their appointment[21]. Obtaining body fluids may require invasive procedures and testing is often expensive[6].

The use of electronic monitoring is limited by its expense[6, 9]. It has been considered to be the gold standard as it provides information that includes the timing of the dose by recording when the medication container was opened[6]. Ideally the opening of the container reflects a patient taking a dose of the medicine; however the container may be opened without a dose being taken[6] or with more than the recommended dose being taken. No information is obtained as to the reasons for non-compliance. When fitted to pills, emerging technology, in the form of transmitters that can send consumption data to a wristwatch,[22] has the potential to become the new gold standard for assessing compliance.

The journals selected were the highest ranking, and the studies published in them assumed to be of the highest quality. It is likely that the reporting of compliance is higher in these publications than others. The exclusion criteria are both strengths and weaknesses of this study as while background variation has been limited, our results cannot be extrapolated to children, adults in institutions, or other routes of administration.

Pharmacists' interventions to improve compliance need a stronger evidence base in relation to the medicines targeted. Without compliance data there can be no true estimate of safety and efficacy[10]. If compliance is poor, efficacy may be underestimated. If poor compliance is compensated by the use of higher doses in clinical trials, there is the risk that after the medicine is marketed, those who are compliant have a higher risk of side-effects[19]. Medications considered to be safe have shown increased toxicity after patient education sessions, also, recommended doses have been reduced after marketing due to the identification of dose-related toxicity[19].

Perceived or genuine lack of benefit is a common cause of non-compliance[14, 23], paradoxically, compliance, even if it is with a placebo, has been shown to improve outcomes[24]. Common sense would indicate that a patient should not continue to take an ineffective medication however determining whether non-compliance or therapeutic failure is the cause is not straightforward.

The correct dose balances risk and benefit; too low a dose can result in therapeutic failure, too high a dose can result in side-effects. Interestingly, non-compliance has been shown to be an effective method of dose titration[25]. Research comparing both positive and negative outcomes from 
medications in relation to dose and compliance in pre- and post-marketing studies is needed.

Analysis by intention to treat (as randomised) may better reflect the real world use of a medication, however, complementing this with correlations of compliance and both effectiveness and side-effect data would assist clinical decision making.

Conclusion

The reporting of compliance in clinical trials is poor and would be improved by including a requirement to include compliance data in the CONSORT guidelines[17]. Ideally, trial results would relate compliance to benefit and adverse effects to provide a stronger evidence base for the use of medications. As recommended by the WHO[9] and SPIRIT [16], two or more methods of measuring compliance should be included in trial protocols and the reporting of trials. Based on feasibility and cost; pill count and patient report with an appropriately valid instrument would be first line, however other measures may be more suitable depending on the primary and secondary outcomes measured; population studied; and validity, reliability, feasibility and cost of the compliance measure.

\section{References}

1. Lozano R, Naghavi M, Foreman K, Lim S, Shibuya K, Aboyans V, et al. Global and regional mortality from 235 causes of death for 20 age groups in 1990 and 2010: a systematic analysis for the Global Burden of Disease Study 2010. Lancet. 2012;380:2095-128.

2. Vos T, Flaxman AD, Naghavi M, Lozano R, Michaud C, Ezzati M, et al. Years lived with disability (YLDs) for 1160 sequelae of 289 diseases and injuries 1990-2010: a systematic analysis for the Global Burden of Disease Study 2010. Lancet. 2012;380:2163-96.

3. Rollason $\mathrm{V}$, Vogt $\mathrm{N}$. Reduction of polypharmacy in the elderly: a systematic review of the role of the pharmacist. Drugs Aging. 2003;20:817-32.

4. Milton JC, Hill-Smith I, Jackson SHD. Prescribing for older people. BMJ. 2008;336:606-9.

5. Nemes MI, Helena ET, Caraciolo JM, Basso CR. Assessing patient adherence to chronic diseases treatment: differentiating between epidemiological and clinical approaches. Cad Saude Publica. 2009;25 Suppl 3:S392-400.

6. $\quad$ Osterberg L, Blaschke T. Adherence to Medication. N Engl J Med. 2005;353:487-97.

7. Vrijens $B$, Vincze $G$, Kristanto $P$, Urquhart J, Burnier M. Adherence to prescribed antihypertensive drug treatments: longitudinal study of electronically compiled dosing histories. BMJ. 2008;336:1114-7.

8. Pharmaceutical Society of Australia. Standard and guidelines for pharmacists performing clinical interventions 2011. Available from: http://www.psa.org.au/download/practiceguidelines/pharmacists-performing-clinical-interventions-guideline.pdf Accessed 28 Sep 2013. 9. World Health Organisation. Adherence to long-term therapies: evidence for action. Switzerland: World Health Organisation; 2003. Available from: http://www.who.int/chp/knowledge/publications/adherence report/en/ Accessed 29 June 2013.

10. Soutter BR, Kennedy MC. Patient compliance assessment in drug trials: usage and methods. Aust N Z J Med. 1974;4:360-4.

11. Jayaraman S, Rieder MJ, Matsui DM. Compliance assessment in drug trials: has there been improvement in two decades? Can J Clin Pharmacol. 2005;12:e251-3.

12. King MA. Medication care : databases, drug use and outcomes. St Lucia, Qld: The University of Queensland; 2003. 
13. Claxton AJ, Cramer J, Pierce C. A systematic review of the associations between dose regimens and medication compliance. Clin Ther. 2001;23:1296-310.

14. Sav A, King MA, Whitty JA, Kendall E, McMillan SS, Kelly F, et al. Burden of treatment for chronic illness: a concept analysis and review of the literature. Health Expect. 2013 (epub ahead of print).

15. Fogarty L, Roter D, Larson S, Burke J, Gillespie J, Levy R. Patient adherence to HIV medication regimens: a review of published and abstract reports. Patient Educ Couns. 2002;46:93-108.

16. Chan AW, Tetzlaff JM, Gotzsche PC, Altman DG, Mann H, Berlin JA, et al. SPIRIT 2013 explanation and elaboration: guidance for protocols of clinical trials. BMJ. 2013;346:e7586.

17. Schulz KF, Altman DG, Moher D, Group C. CONSORT 2010 statement: updated guidelines for reporting parallel group randomised trials. BMJ. 2010;340:c332.

18. Matsui D. Strategies to measure and improve patient adherence in clinical trials. Pharm Med. 2009;23:289-97.

19. Smith DL. Patient Nonadherence in Clinical Trials: Could There Be a Link to Postmarketing Patient Safety? Drug Information Journal. 2012;46:27-34.

20. Garfield S, Clifford S, Eliasson L, Barber N, Willson A. Suitability of measures of self-reported medication adherence for routine clinical use: a systematic review. BMC Med Res Methodol. 2011;11:149.

21. Cramer JA, Scheyer RD, Mattson RH. Compliance declines between clinic visits. Arch Intern Med. 1990;150:1509-10.

22. Felder RA. Testimony of Robin A Felder PhD, Professor of Pathology, Associate Director Clinical Chemistry, The University of Virginia School of Medicine, before the Senate Special Committee on Aging, April 22nd, 2010. Washington DC: 2010.

23. DiMatteo MR, Giordani PJ, Lepper HS, Croghan TW. Patient adherence and medical treatment outcomes: a meta-analysis. Med Care. 2002;40:794-811.

24. Simpson SH, Eurich DT, Majumdar SR, Padwal RS, Tsuyuki RT, Varney J, et al. A meta-analysis of the association between adherence to drug therapy and mortality. BMJ. 2006;333:15.

25. Steiner JF, Fihn SD, Blair B, Inut TS. Appropriate reductions in compliance among wellcontrolled hypertensive patients. J Clin Epidemiol. 1991;44:1361-71.

26. Brighton TA, Eikelboom JW, Mann K, Mister R, Gallus A, Ockelford P, et al. Low-dose aspirin for preventing recurrent venous thromboembolism. N Engl J Med. 2012;367:1979-87.

27. Comi G, Jeffery D, Kappos L, Montalban X, Boyko A, Rocca MA, et al. Placebo-controlled trial of oral laquinimod for multiple sclerosis. N Engl J Med. 2012;366:1000-9.

28. Donnez J, Tatarchuk TF, Bouchard P, Puscasiu L, Zakharenko NF, Ivanova T, et al. Ulipristal acetate versus placebo for fibroid treatment before surgery. N Engl J Med. 2012;366:409-20.

29. McCarthy PL, Owzar K, Hofmeister CC, Hurd DD, Hassoun H, Richardson PG, et al. Lenalidomide after stem-cell transplantation for multiple myeloma. N Engl J Med. 2012;366:1770-81. 30. Morrow DA, Braunwald E, Bonaca MP, Ameriso SF, Dalby AJ, Fish MP, et al. Vorapaxar in the secondary prevention of atherothrombotic events. N Engl J Med. 2012;366:1404-13.

31. Parving HH, Brenner BM, McMurray JJ, de Zeeuw D, Haffner SM, Solomon SD, et al. Cardiorenal end points in a trial of aliskiren for type 2 diabetes. N Engl J Med. 2012;367:2204-13.

32. Roe MT, Armstrong PW, Fox KA, White HD, Prabhakaran D, Goodman SG, et al. Prasugrel versus clopidogrel for acute coronary syndromes without revascularization. $\mathrm{N}$ Engl J Med. 2012;367:1297-309.

33. Sandborn WJ, Ghosh S, Panes J, Vranic I, Su C, Rousell S, et al. Tofacitinib, an oral Janus kinase inhibitor, in active ulcerative colitis. N Engl J Med. 2012;367:616-24.

34. Scher HI, Fizazi K, Saad F, Taplin ME, Sternberg CN, Miller K, et al. Increased survival with enzalutamide in prostate cancer after chemotherapy. N Engl J Med. 2012;367:1187-97.

35. Verstovsek S, Mesa RA, Gotlib J, Levy RS, Gupta V, DiPersio JF, et al. A double-blind, placebocontrolled trial of ruxolitinib for myelofibrosis. N Engl J Med. 2012;366:799-807. 
36. Ledermann J, Harter P, Gourley C, Friedlander M, Vergote I, Rustin G, et al. Olaparib maintenance therapy in platinum-sensitive relapsed ovarian cancer. N Engl J Med. 2012;366:1382-

92.

37. Mega JL, Braunwald E, Wiviott SD, Bassand JP, Bhatt DL, Bode C, et al. Rivaroxaban in patients with a recent acute coronary syndrome. N Engl J Med. 2012;366:9-19.

38. Schwartz GG, Olsson AG, Abt M, Ballantyne CM, Barter PJ, Brumm J, et al. Effects of dalcetrapib in patients with a recent acute coronary syndrome. N Engl J Med. 2012;367:2089-99.

39. Thigpen MC, Kebaabetswe PM, Paxton LA, Smith DK, Rose CE, Segolodi TM, et al.

Antiretroviral preexposure prophylaxis for heterosexual HIV transmission in Botswana. N Engl J Med. 2012;367:423-34.

40. Van Damme L, Corneli A, Ahmed K, Agot K, Lombaard J, Kapiga S, et al. Preexposure prophylaxis for HIV infection among African women. N Engl J Med. 2012;367:411-22.

41. Thadhani R, Appelbaum E, Pritchett $Y$, Chang $Y$, Wenger J, Tamez $H$, et al. Vitamin D therapy and cardiac structure and function in patients with chronic kidney disease: the PRIMO randomized controlled trial. JAMA. 2012;307:674-84.

42. Fried MW, Navarro VJ, Afdhal N, Belle SH, Wahed AS, Hawke RL, et al. Effect of silymarin (milk thistle) on liver disease in patients with chronic hepatitis $C$ unsuccessfully treated with interferon therapy: a randomized controlled trial. JAMA. 2012;308:274-82.

43. Lok CE, Moist L, Hemmelgarn BR, Tonelli M, Vazquez MA, Dorval M, et al. Effect of fish oil supplementation on graft patency and cardiovascular events among patients with new synthetic arteriovenous hemodialysis grafts: a randomized controlled trial. JAMA. 2012;307:1809-16.

44. Paton NI, Goodall RL, Dunn DT, Franzen S, Collaco-Moraes Y, Gazzard BG, et al. Effects of hydroxychloroquine on immune activation and disease progression among HIV-infected patients not receiving antiretroviral therapy: a randomized controlled trial. JAMA. 2012;308:353-61.

45. Sesso HD, Christen WG, Bubes V, Smith JP, MacFadyen J, Schvartz M, et al. Multivitamins in the prevention of cardiovascular disease in men: the Physicians' Health Study II randomized controlled trial. JAMA. 2012;308:1751-60.

46. Solomon SD, Zile M, Pieske B, Voors A, Shah A, Kraigher-Krainer E, et al. The angiotensin receptor neprilysin inhibitor LCZ696 in heart failure with preserved ejection fraction: a phase 2 double-blind randomised controlled trial. Lancet. 2012;380:1387-95.

47. van der Graaf WT, Blay JY, Chawla SP, Kim DW, Bui-Nguyen B, Casali PG, et al. Pazopanib for metastatic soft-tissue sarcoma (PALETTE): a randomised, double-blind, placebo-controlled phase 3 trial. Lancet. 2012;379:1879-86.

48. Burant CF, Viswanathan P, Marcinak J, Cao C, Vakilynejad M, Xie B, et al. TAK-875 versus placebo or glimepiride in type 2 diabetes mellitus: a phase 2, randomised, double-blind, placebocontrolled trial. Lancet. 2012;379:1403-11.

49. Fleshner NE, Lucia MS, Egerdie B, Aaron L, Eure G, Nandy I, et al. Dutasteride in localised prostate cancer management: the REDEEM randomised, double-blind, placebo-controlled trial. Lancet. 2012;379:1103-11.

50. Gallwitz B, Rosenstock J, Rauch T, Bhattacharya S, Patel S, von Eynatten M, et al. 2-year efficacy and safety of linagliptin compared with glimepiride in patients with type 2 diabetes inadequately controlled on metformin: a randomised, double-blind, non-inferiority trial. Lancet. 2012;380:475-83. 
Table 1 Articles included in the systematic review

\begin{tabular}{|c|c|c|c|c|}
\hline Reference & Condition & Treatment/Duration & Method & Compliance \\
\hline \multicolumn{5}{|l|}{ NEJM } \\
\hline $\begin{array}{l}\text { Comi et. } \\
\text { al.[27] }\end{array}$ & Multiple sclerosis & $\begin{array}{l}\text { laquinimod } 0.6 \mathrm{mg} \text { or placebo, once } \\
\text { daily; } \\
\text { duration } 24 \text { months }\end{array}$ & Not reported & Not reported \\
\hline $\begin{array}{l}\text { Donnez et. al. } \\
\text { [28] }\end{array}$ & Fibroids & $\begin{array}{l}\text { ulipristal acetate } 5 \mathrm{mg}, 10 \mathrm{mg} \text { or } \\
\text { placebo, once daily; } \\
\text { duration up to } 13 \text { weeks }\end{array}$ & Not reported & Not reported \\
\hline $\begin{array}{l}\text { McCarthy et. } \\
\text { al.[29] }\end{array}$ & Multiple myeloma & $\begin{array}{l}\text { lenalidomide } 10 \mathrm{mg} \text { (range, } 5 \text { - 15mg) } \\
\text { or placebo, daily; } \\
\text { median follow-up } 18 \text { months }\end{array}$ & Not reported & Not reported \\
\hline $\begin{array}{l}\text { Morrow et. } \\
\text { al.[30] }\end{array}$ & $\begin{array}{l}\text { Atherothrombotic } \\
\text { events }\end{array}$ & $\begin{array}{l}\text { vorapaxar } 2.5 \mathrm{mg} \text { or placebo, once } \\
\text { daily; } \\
\text { median follow-up } 30 \text { months }\end{array}$ & Not reported & Not reported \\
\hline Roe et. al.[32] & $\begin{array}{l}\text { Acute coronary } \\
\text { syndromes }\end{array}$ & $\begin{array}{l}\text { loading dose prasugrel } 30 \mathrm{mg} \text { or } \\
\text { clopidogrel } 300 \mathrm{mg} \text {; } \\
\text { maintenance dose prasugrel } 10 \mathrm{mg} \\
\text { (5mg if aged } \geq 75 \text { years } /<60 \mathrm{~kg} \text { ) or } \\
\text { clopidogrel } 75 \mathrm{mg} \text {, daily; } \\
\text { average duration } 14.8 \text { months }\end{array}$ & Not reported & Not reported \\
\hline $\begin{array}{l}\text { Sandborn et. } \\
\text { al.[33] }\end{array}$ & Ulcerative colitis & $\begin{array}{l}\text { tofacitinib } 0.5 \mathrm{mg}, 3 \mathrm{mg}, 10 \mathrm{mg} \text { or } \\
15 \mathrm{mg} \text { or placebo, twice daily; } \\
\text { duration } 8 \text { weeks }\end{array}$ & Not reported & Not reported \\
\hline Scher et. & Prostate cancer & enzalutamide $160 \mathrm{mg}$ ( 4 x 40mg & Not reported & Not reported \\
\hline
\end{tabular}


al.[34]

Verstovsek et. Myelofibriosis al.[35]

Ledermann Ovarian cancer

et.al.[36]

Mega et. Acute coronary

al.[37]

Schwartz et. Acute coronary

al[38]

Thigpen et.

al.[39]

Van Damme

et. al.[40] capsules) or matching placebo, once

daily;

median duration enzalutamide 8.3

months, placebo 3 months

ruxolitinib $15 \mathrm{mg}$ for a platelet count of $100 \times 10^{9}-200 \times 10^{9}$ per litre, $20 \mathrm{mg}$ for a count $>200 \times 10^{9}$ per litre or

placebo, twice daily;

median follow-up 32 weeks

\section{olaparib 400mg or placebo, twice}

daily;

median duration olaparib 206.5 days,

placebo 141 days

rivaroxaban $2.5 \mathrm{mg}, 5 \mathrm{mg}$ or placebo, Not reported

twice daily;

mean duration 13 months

dalcetrapib 600mg or placebo, daily; Not reported

median follow-up 31 months

tenofovir disoproxil fumarate and

emtricitabine (TDF-FTC) or matching

placebo, once daily;

median follow-up 1.1 years

TDF-FTC or placebo, once daily;

Duration 52 drug weeks and 8 follow-

up

onthly pill count;

Self-report (preceding 3 days)

Blood levels

Pill count

Self-report

Blood levels

JAMA

Thadhani

et.al.[41]
Cardiac structure

in patients with

kidney disease paricalcitol 2ug or matching placebo, Not reported

daily;

duration 48 weeks
Not reported

Mean adherence $85 \%$ olaparib, $96 \%$ placebo

93.9\% (2.5mg), 94.0\% (5mg), \& 94.6\% (placebo) of patients were $\geq 85 \%$ compliant

$89 \%$ of patients in both groups had at least $80 \%$ adherence during the time they were receiving the study drug 84.1\% TDF-FTC, $83.7 \%$ placebo; 94.4\% TDF-FTC,94.1\% placebo Not presented

Consistent with ingestion of study drug on $88 \%$ of days;

$95 \%$ of participants usually or always took the drug;

Revealed much lower levels of adherence

Not reported 
Fried et. Liver disease in

al.[42] patients with

Hepatitis C

Lok et. al.[43] Cardiovascular events

Paton et.

HIV

al.[44]

Sesso et. Cardiovascular al.[45]

disease

The Lancet

Solomon et. Heart failure al.[46]

van der Graaf Soft-tissue et. al. [47] sarcoma

Burant et. Type 2 diabetes silymarin $420 \mathrm{mg}$ ( 3 capsules of silymarin and 2 placebo), $700 \mathrm{mg}$ silymarin ( 5 capsules of silymarin) or placebo (5 capsules), three times daily

duration 24 weeks

fish oil $(4 \times 1 \mathrm{~g})$ or matching placebo, daily;

duration 12 months

hydroxychloroquine $400 \mathrm{mg}$ ( $2 \mathrm{x}$

$200 \mathrm{mg}$ tablets) or matching placebo, once daily

duration 48 weeks

multivitamin or placebo, daily; median follow-up 11.2 years

Initially LCZ696 50mg or valsartan $40 \mathrm{mg}$, twice daily, titrated to LCZ696 $200 \mathrm{mg}$ or valsartan $160 \mathrm{mg}$, twice daily over 2-4 weeks duration 12-week main study period and 24-week extension

pazopanib $800 \mathrm{mg}$ or placebo, once daily with no cross-over; median duration pazopanib 4.6 months, placebo 1.6 months

TAK-875 $(6.25,25,50,100$ or $200 \mathrm{mg}) \quad$ Not reported

Not reported

Not reported
$95 \%$ of participants met or exceeded an $80 \%$ threshold for adherence (95.2\% silymarin 420-mg, 93.0\% silymarin $700 \mathrm{mg}, 91.8 \%$ placebo) a percentage of the medicatior dose cups dispensed compared with cups returned at follow-up)

EPA incorporation into endogenous cells measured by gas-liquid chromatography

Self-report (questioned about changes to the study medication schedule, missed capsules in the previous 2 weeks, missed capsules since the previous visit, and any periods of treatment interruption) Self-report (annual questionnaire) Shown to be highly reliable in physicians, as taking at least twothirds of the pills

Adherence confirmed

$>90 \%$ of prescribed doses taken by $81 \%$ of patients in the hydroxychloroquine group and $83 \%$ in the placebo group

$76.8 \%$ multivitamin, $77.1 \%$ placebo at 4 years; $72.3 \%$ multivitamin, $70.7 \%$ placebo at 8 years; $67.5 \%$ multivitamin, $67.1 \%$ placebo at the end of follow-up

Not reported

Not reported

$98 \%$ to $100 \%$ 
al.[48]

Fleshner et. Prostate cancer

al.[49]

Gallwitz et. Type 2 diabetes

al.[50] or glimepiride $4 \mathrm{mg}$ or placebo, once

daily;

duration 12-weeks

dutasteride $0.5 \mathrm{mg}$ or matching

placebo, once daily;

duration 3 years

linagliptin $5 \mathrm{mg}$ tablet and one

placebo capsule once daily or one

glimepiride(1-4mg titrated dose)

capsule and once placebo tablet,

once daily;

duration 104 weeks
Mean $97 \%$ in both groups

Pill count number of tablets/capsules At least $93 \%$ of patients were taken, as a percentage of the number adherent

that should have been taken. Non-

adherence $(<80 \%$ or $>120 \%$ ) was

treated as a protocol violation 